\section{OBSERVATIONS ON TWENTY-FIVE CASES OF PROSTATECTOMY.}

BY

RALPH COYTE, M.B., B.S.LoND., F.R.C.S.,

ASSISTANT SURGeON TO ALL SAINTS' hospital aND THE QIEEN'S hospital FOR CHILDREN ; SURGICAL REGISTRAR, PRINCE OF WALES'S HOSPITAL, TOTTENHAM.

Durrag 1925 I had under my care in All Saints' Hospital 25 cases of enlarged prostate for which prostatectomy was performed. These cases I have subsequently followed up in the out-patient department for the ensuing two months or longer.

The average age of the patients was 60 -the youngest being 49 and the eldest 73 . The mortality was one; this patient died on the sixteenth day after operation from a pulmonary embolus. He exhibited the usual symptoms; he was taken with a sudder desire to defaecate, and while on the bed-pan fell back dead.

Of the 25 operations, 20 were by the one-stage and 5 by the two-stage method. In the selection of method I have been guided by three factors:

(a) The Clinical Picture.-Patients exhibiting a dry furred tongue, persistent headaches, loss of appetite (particularly for meat), and the passage of scanty urine are only suitable for a two-stage operation.

(b) Cystoscopy.-This I have done as a routine, and is, in my opinion, of the greatest value, in that it demonstrates the degree of sepsis within the bladder. A gross degree is only suitable for a two-stage operation. While the cystoscope is in position the kidney function can also be tested by intravenous injection of indigo-carmine.

(c) Trea Concrntration T'sest.-Where the final concentration falls below the 1.3 mark I think the two-stage operation should be adopted.

As regards the actual operation, the first 8 cases of this series were treated by putting a large drainage tube (bore 1 in.) in the bladder, without packing the prostatic carity. In two of these cases fairly severe hatemorrhage orcured two hours after operation. In the remaining 17 cases $I$ have packed the prostatic cavity for forty-eight hours. I find there is often a little bleeding on removing the parking, but it is never serious: and although the procedure causes a certain amount of pain this can easily he controlled by morphine. I alwars pack the cavity with two fingers in the bladder, and without widely retracting the edges of the bladder wall, as I consider that the latter procedure somewhat increases the shock of the opreration.

The tube is removed on the sixth day, and the patient then washed per urethram with a solution of 1 in 10,000 silver nitrate once a day. The average time taken for the suprapubic wound to heal has been twenty-four days-the quickest being, sixteen, and the longest thirty-five days. The patients taking the longest time to heal have all been markedly obese.

Complications met with have been epididymitis in 7 cases; these all subsequently cleared up. There was one case in which the suprapubic wound reopened five weeks after discharge from hospital; this man had at the time of operation a stricture in the penile urethra which had previously been dilated; after operation he did not come up for treatment as advised, but on dilatation of his stricture the fistula rapidly closed. In one case the symptoms were not relieved by the operation, and by posterior urethroscopy I discovered that this man had developed an obstruction in the shape of a prostatic ledge. This 1 dealt with by diathermy through the wrethroscope, and the patient is now in good health. The remaining patients made uneventful recoveries, and have since been quite well.

Sections of the prostates were made after renoral. In one case an early adenocarcinoma was found to have commenced: this man is still quite well nine months after operation. Some of the glands after removal showed small areas of normal prostatic tissue around the adenomatous portion, and the fatal case showed normal prostatic tissue remaining around the cavity. These latter findings show that it is impossible to remore the prostate completely, and that the operator, must lcave sufficient normal tissue for a further potential adenomatous enlargement.

\section{THE INHIBITION OF INSULIN ACTION BY TOXAEMIAS AND ITS EXPLANATION.}

\author{
A Preliminary Commianication.
}

BY

R. D. LAWRENCE, M.D., *

CheMitcal Pathologist, KiNG'S COLLEge hospital:

THE effect of toxaemias and different forms of sepsis in reducing insulin action in diabetes is one of its chief puzzles and the greatest weakness of insulin therapy. All workers are agreed that sepsis and infections make diabetes worse, are a common immediate cause of coma, and that their onset requires a greatly increased dosage of insulin to produce the same effect. The problem of this inhibition of insulin action is therefore of great physiological and therapeutic importance. It was thought that the catese that prevented the usual action of insulin in septic conditions would most likely be the production of a metabolic condition that failed to respond to insulin in the usual way, and the failure would not be due to direct chemicil inhibition of insulin by the circulating toxins.

The easiest way to attack the problem seemed to be to try to produce an insulin-resistant condition in normal animals by toxins and to observe any accompanying changes which might account for the failure of insulin action. Various toxins have been tried on rabbits, and the clearest results have so far been obtained by diphtheria toxin: With this a condition has been produced in which the porer of insulin to reduce blood sugar has been greatly diminished and sometimes abolished altogether. At the same time extensive pathological changes have been observed in the thyroid and adrenal glands which would appear to be the cause underlying the inhibition of insulin action. The details of these experiments and a number of curious observed facts in connexion with insulin action will be published soon in the British Journal of Experimental Pathology, but it is considered desirable now to give a summary of the work, as it is of clinical as well as experimental interest.

\section{Rablit Experiments.}

It has been found that when normal rabbits are given a dose of diphtheria toxin which kills them in about fou to eight days, a dose of insulin which previously caused a considerable diop of blood sugar fails to do so. This usually does not take place on the first day, when the animal is at the height of its pyrexial reaction, but becomes most noticcable when the action of the toxin is fully established. On certain dars, indeed, insulin has been observed to raise, and not to lower, the blood sugar concentration. These points have been repeatedly observed after the injection of diphtheria toxin.

Histologically, striking changes have been observed in the thyroid and adrenal glands of these animals, and to a greater degree than in the other organs examined. The thrroids showed great congestion, disappearance of the colloid, and destruction and confluence of many of the alreoli. In the adrenals congestion and signs of complete exhanstion and disappearance of the lipoid were observed. Such changes in the adrenal are a well known result of death from diphtheria toxin, and are, indeed, used to distinguish true diphtheria from diphtheroid organisms.

The Significance of these Experiments.

The thyroid and adrenal glands and their extracts are known to be direct physiological antagonists to insulin. This has been shown quite clearly in animals and in man by the simultaneous injection of adrenaline, which is found to prevent the usual action of insulin in lowering blood sugar. It has also been shown that thyroid feeding in animals greatly reduces the usual action of insulin. And, from the clinical point of view, the disturbance of carbohydrate metabolism and resulting glycosuria in hyperthyroidism and the hyperadrenalism of excitement is well known. It would appear clear, therefore, that an agent which stimulates the thyroid or adrenal, singly or together, would antagonize the usual action of insulin. 
In the experiments on rabbits such changes in the thyroid and adrenal have been found, and would appear to account for the failure of insulin action after diphtheria toxin. There is much evidence that in all infections there is a stimulation of these two glands, which would account for the increase in the sererity of diabetes and the failure of insulin, either relative or absolute, so constantly found in infected conditions in the diabetic. Furthermore, there is evidence that the same disturbance of carbohydrate metabolism takes place in a much slighter and less noticeable degree in normal individuals who are suffering from infections. Such evidence will be considered in detail in the more complete description of these experiments shortly to be published.

\section{Further Clinical Evidence.}

An analysis of the cases of diabetes recorded as being resistant to insulin and not responding to it in the usual manner also affords evidence that the thyroid and adrenals are the usual agents which antagonize the action of insulin in these " insulin resistant" cases. Apart from cases of diabetes with infections which do not respond to insulin in the usual way, a number of cases are recorded which require enormous doses of insulin to obtain the usual therapeutic effects. Many of these cases were definitely complicated by hyperthyroidism, and most of the others seemed to be of the nervous excitable type which we may justifiably associate with overactivity of the sympathetic nervous system, probably caused by the thyroid or adrenal or both acting together. I have recently had a case of severe diabetes in whom the onset of hyperthyroidism (Graves's disease) produced coma in spite of the usual dose of 60 units of insulin a day, and required 140 units a day to control the blood sugars on a constant diet. The use of iodine to control the hyperthyroidism reduced the insulin requirement to the previous amount, and the withdrawal of the iodine again increased the insulin requirements.

An attempt has been made to control the overactivity of the sympathetic nervous system complicating diabetes by the use of ergotamine. But although evidence has been obtained that it does decrease sympathetic activity and so increases insulin activity, it would appear to be impossible to give it to man in sufficient doses to exercise any appreciable therapeutic effect on diabetes.

\section{Conclusions.}

It is suggested from experimental and clinical evidence that toxins and infections antagonize insulin action by a stimulation of the thyroid and adrenal glands. These glands are direct physiological antagonists to insulin action, and their overactivity makes diabetes worse and prevents the usual action of insulin

The effect of various toxins and infections in this respect is being investigated. But the evidence in support of the above hypothesis seems sufficiently clear to warrant this preliminary communication.

\section{THE MODERN HOSPITAL CONCEPTION.*}

\section{N. BISHOP HARMAN, M.A., M.B.CANTAB.,}

$$
\text { F.R.C.S.Eva., }
$$

SENTOR OPHTHALMIC SURGEON TO THE WEST LONDON HOSPITAL, ETC.

THE characteristics of hospitals have varied according to the time and place of their working. Our present-day ideas and practices may seem strange to our sons' sons a hundred years hence, just as our achievements would most certainly bo amazing to our forefathers of a hundred years ago.

In discussing the modern hospital conception it will be well to keep in mind ancient practice. There is a stimulus in the reminder of the high ideals that have been evident even when hospitals were as bad as they well could be. Further, the remembrance of the diversity of aim displayed ${ }^{*}$ Read at the inaugural meeting of the Windsor Division, October 15th, by the founders of old hospitals will prevent us falling into the bad habit of thinking that some one line of policy, and particularly the one we are familiar with, is the one and only policy to be countenanced. The study of history has this sure advantage-we shall discover such a wide range of precedents for diversities in practice that wo are encouraged to take wide views of present-day practice and what may come out of it.

\section{Early Hospitals.}

Thero seems a common belief that hospitals are, and have been always, places for the treatment of the sick poor; als' that they only came into being during the Christian era. It would bo foolish to deny that both these beliefs are substantially true. There has been a dominance of the idea of the " house of pity" in the hospital, and pity has been a characteristic mark of Christianity. Yet in point of fact both these beliefs are wrong. The origin of the word " hospital" shows that hospitals were not primarily places for the sick, and we in this country use the word for other purposes. I have only to call to vour mind three celebrated hospitals founded within the mediaeval city of London, and still existing in much their original form, to prove the diversity of usage of this word: Christ's Hospital on one side of Smithfield, and St. Bartholomew's Hospital on another, and the Royal Hospital of St. Katherine's by tho Tower-all three famous throughout tho country. Yet tio first of these was and is a school, the second a place for the sick poor-for the "recreation of poor men "-and tho third an almshouse. A very proper trinity of benevolence, all covered by this one name. And these three are by no means exceptional; many more such throughout the country survivo to this day.

Again, places set apart for the treatment of the sick were not always " houses of pity," places for the sick poor; neither are they atways so now. The temples of Aesculapius, whose staff wo claim as our ensign, were the classical prototypes of what a complete hospital might be. There were within the precincts sick wards, bathing establishments, gymnasia, libraries, sleeping porches for guests, a theatre, and the temple proper. The provision was as wide in its embrace of human needs as the most moderin of spais. I do not think we could do better than keep in mind this ancient practice in building up our own conception of the modern hospital, and particularly the fact that they were not places for the poor alone, but for all classes within the classic city state. To-day in the United States of America, where our mother tongue is spoken by three times as many persons as speak it in these islands, the word " hospital" "used in relation to the sick does not mean solely a house of pity; all classes look upon it as indicating a place for them if and when necessity arises.

Houses of Pity.

In this country there hangs about our idea of the hospital an obsession that is an inheritance from mediaeval tradi. tion. Most of our hospitals, when places for the sick, were houses of pity, founded by pious benefactors, who in the current thought of the time sought to make expiation for their sins by their benefactions. These foundations were for the most part under ecclesiastical control, and their value to the community rose and fell with the purity and corruption of monasticism. The ideas that arose from false conceptions of sanctity and the rigid conventual isolation of the servants of the sick in olden times cannot be better illustrated than by a reference to the dictum of St. Chrysostom, the founder of one of the earliest Christian hospitals, to whom we owe one of the most beautiful of the prayers in Christian books of devotion, which fittingly finds a place in the English Book of Common Prajer; this saintly man tried to persuade the deaconesses under Olympia to go unwashed! The struggle between sanctity and soap lasted long. A thousand years later we find St. Vincent de Paul, the reformer of French hospitals, protesting against the isolation of the nursing sisters which put them under the influence of the priest rather than the physician. Ho said : "My daughters, you are not religious in the technical sense,
and if there should be found some marplot among you to say "it is 